\title{
Transmission dynamics of intramammary infections caused by Corynebacterium species
}

\author{
Gunnar Dalen, ${ }^{*} \dagger^{1}$ Amira Rachah, ${ }^{*}$ Håvard Nørstebø, ${ }^{\star} \dagger$ Ynte H. Schukken, $\neq \S \#$ Yrjö T. Gröhn,\# \\ John W. Barlow,ll and Olav Reksen* \\ *Norwegian University of Life Sciences, Faculty of Veterinary Medicine, Department of Production Animal Clinical Sciences, \\ PO Box 8146 Dep., N-0033 Oslo, Norway \\ †TINE SA, PO Box 58, N-1430 Ås, Norway \\ ¥GD Animal Health, Arnsbergstraat 7, 7400 AA Deventer, the Netherlands \\ $\S$ Department of Animal Sciences, Wageningen University, 6708 PB Wageningen, the Netherlands \\ \#Department of Population Medicine and Diagnostic Sciences, Cornell University, Ithaca, NY 14850 \\ \|Department of Animal and Veterinary Sciences, University of Vermont, Burlington 05405
}

\begin{abstract}
The development of reliable models for transmission of intramammary infections (IMI) is the subject of extensive research. Such models are useful to enhance the identification and understanding of factors that affect pathogen-specific IMI dynamics. Longitudinal transmission models are valuable for predicting infection outbreak risks, quantifying the effectiveness of response tactics, and performing response planning. In this work, we focused on modeling Corynebacterium spp. by using a compartmental model. Previous investigations have considered modeling the transmission dynamics of several bacterial pathogens, but not Corynebacterium spp. We established a Corynebacterium spp. Susceptible-Infectious-Susceptible (SIS) model. We simulated the model numerically by using parameters that we estimated by a generalized linear model approach, using month of study as the time variable. The data, from which the parameters of the model were estimated, were obtained in a field trial conducted in 2 US dairy herds. Altogether, 786 cows were sampled at least once during the 13-mo study period. The total number of quarter milk cultures and cases of IMI caused by $\mathrm{Co}$ rynebacterium spp. were 11,744 and 556, respectively, in farm A; the corresponding figures for farm B were 11,804 and 179. Our modeling study included only transmission from persistent IMI caused by Corynebacterium spp. within the lactation pens. The rate of new infections was significantly related to preexisting IMI in both farms, underscoring the importance of preexisting Corynebacterium spp. IMI for the transmission of Corynebacterium spp. within lactation pens. The estimated
\end{abstract}

Received May 31, 2017.

Accepted August 25, 2017.

${ }^{1}$ Corresponding author: gunnar.dalen@nmbu.no basic reproduction numbers $\left(R_{0}\right)$ in the 2 farms were 1.18 and 0.98 , respectively. The nonsignificant disparity in $R_{0}$ was associated with significant differences in cure rates between farms.

Key words: intramammary infection, Corynebacterium spp., transmission model

\section{INTRODUCTION}

Mastitis is one of the economically most important diseases in dairy production (Halasa et al., 2007; Hogeveen et al., 2011). Much of the economic loss is due to reduced milk production following subclinical mastitis (Hogan et al., 2016). Intramammary infections with Corynebacterium spp. are generally mild with limited milk production loss. However, significant elevations in SCC have been observed (Brooks et al., 1983; Brooks and Barnum, 1984a). Although Corynebacterium spp. are classified as minor pathogens (Brooks and Barnum, 1984b; Harmon, 1994; Blagitz et al., 2013), the increased prevalence of Corynebacterium spp. IMI in some modern dairy farms (Pitkälä et al., 2004) warrants further investigation into the specific properties and roles of the bacteria.

Some authors have reported a protective effect of Corynebacterium spp. IMI against IMI caused by other pathogens (Rainard and Poutrel, 1988; Lam et al., 1997a), whereas others report an increased risk of mastitis (Pankey et al., 1985; Berry and Hillerton, 2002; Parker et al., 2007). When investigating the relationship between secondary infections and a preexisting IMI by Corynebacterium spp., Parker et al. (2007) suggested that the diverging effects reported for Corynebacterium spp. IMI were due to the increased disposition for clinical mastitis of glands with a preexisting IMI. There is also evidence that Corynebacterium bovis can colonize the teat canal without affecting the udder past Furstenberg's rosette (Black et al., 1972). 
Mathematical models are powerful tools for understanding infection dynamics by providing predictions about the potential transmission of infections and the effectiveness of control measures (Magal and Ruan, 2008; Otto and Day, 2011). Pathogen-specific transmission patterns have been described for other major and minor mastitis pathogens (Lam, 1996; Zadoks et al., 2002; White et al., 2006; Reksen et al., 2012; Barlow et al., 2013), but not for Corynebacterium spp. The basic reproduction number, $\boldsymbol{R}_{\mathbf{0}}$, is used in compartmental transmission models to determine transmission of a disease at the population level. It is defined as the number of secondary cases that one infectious case can produce if introduced into a susceptible population (Grossman, 1980; Diekmann et al., 1990; Hethcote, 2000). Modeling the progression of a disease depends on appropriate parameter values that are often unknown and must be estimated from field data. In this study, we have used a generalized linear model for parameter estimation. The parameters estimated were used in a deterministic state-transition model to describe the transmission dynamics of Corynebacterium spp. from preexisting IMI within lactation pens.

The main aim of this study was to develop a novel mathematical description of the transmission dynamics of Corynebacterium spp. IMI. Specifically, we first wanted to assess the importance of preexisting IMI by Corynebacterium spp. on new IMI caused by this group of bacteria. Second, we wanted to compare transmission parameters and cure rates for Corynebacterium spp. IMI between 2 US dairy farms with differing prevalences of Corynebacterium spp. IMI.

\section{MATERIALS AND METHODS}

\section{Field Study}

Data were obtained from a 13-mo longitudinal observational study in 2 commercial Holstein dairy herds (one in New York and one in Vermont). Cows were housed in pens of approximately 100 cows and milked 3 times per day. In farm A, the monthly mean number of lactating cows was 319 , the mean milk production per cow per day was $32.7 \mathrm{~kg}$, and the average cow composite SCC was 404,000 cells/mL. In farm B, the monthly mean number of lactating cows was 346, the mean milk production per cow per day was $35.0 \mathrm{~kg}$, and the average cow composite SCC was 292,000 cells/ $\mathrm{mL}$. The herds participated in a DHIA program with monthly milk quality testing. Both farms had reliable identification of animals and used standardized mastitis control practices, including pre- and postmilking teat disinfection and blanket dry-cow therapy. Further details on the herds, microbial analyses, and sampling framework have been published previously (Reksen et al., 2012; Barlow et al., 2013).

Quarter milk samples were collected monthly from approximately 200 lactating cows on each farm. Additional samples were collected within $3 \mathrm{~d}$ after parturition and when animals were moved to or from the lactation compartment.

Trained field technicians collected the scheduled monthly samples. Selected farm personnel, who had received training for this, obtained the additional samples. All samples were collected according to recommended guidelines (Hogan et al., 1999). Samples collected monthly were kept on ice after collection and during transport to the laboratory, where they were frozen before microbiological analyses. Additional samples collected by farm personnel were frozen immediately after collection. Samples were thawed in the laboratory and bacteriological culture was performed according to standard procedures (Hogan et al., 1999). Samples with culture results presenting more than 3 morphologically different colony types were treated as contaminated and excluded from further analyses.

A quarter was considered to have an IMI with $\mathrm{Co}^{-}$ rynebacterium spp. when meeting at least one of the following criteria: $(1) \geq 1,000 \mathrm{cfu} / \mathrm{mL}$ of the pathogen were cultured from a single sample, $(2) \geq 500 \mathrm{cfu} / \mathrm{mL}$ of the pathogen were cultured from 2 out of 3 consecutive milk samples, (3) $\geq 100 \mathrm{cfu} / \mathrm{mL}$ of the pathogen were cultured from 3 consecutive milk samples, or (4) $\geq 100$ $\mathrm{cfu} / \mathrm{mL}$ of the pathogen were cultured from a clinical sample (Zadoks et al., 2002). A case was considered clinical when there was abnormal milk, with or without pain or swelling in the udder, or systemic signs such as anorexia, lethargy, or elevated rectal temperature (Harmon, 1994). Positive bacterial cultures that did not meet any of the above criteria were classified as representing a transient colonization with Corynebacterium spp.

\section{Statistical Analysis}

Statistical analysis was conducted using SAS software (version 9.1; SAS Institute, Inc., Cary, NC). Transmission parameters $(\beta)$ and cure rates $(\alpha)$ were calculated using the generalized linear model approach (PROC GENMOD). Evidence of overdispersion was evaluated and models were subsequently adjusted using an overdispersion parameter estimated from the ratio of the Pearson Chi-squared estimate divided by the remaining degrees of freedom (Pscale option).

The transmission parameter $(\beta)$ was estimated in a linear model with number of new Corynebacterium spp. IMI events in each monthly interval $\left(I_{M}\right)$ as the outcome; $S=$ quarter-days in a susceptible udder, $I=$ 
quarter-days infected, $N=$ total quarter-days in each interval (study month), $\beta^{*}$ is the intercept in the equation $\ln \left(I_{M}\right)=\beta^{*}+\ln \frac{S I}{N}$, and the transmission coefficient $\beta$ is expressed as $\mathrm{e}^{\beta}$. A log link, assumption of a negative binomial distribution, and offset $\ln \frac{S I}{N}$ (Zadoks et al., 2002) were used. Wald 95\% confidence limits were used to compare transmission parameters between farms. To evaluate the effect of an existing Corynebacterium spp. IMI on transmission dynamics, we compared the fit of a model with the complete offset term included and a model without the term $I / N$ included in the offset by comparing the $2 \times \log$-likelihood ratios.

The cure rate $(\alpha)$ was estimated with number of cured quarters from Corynebacterium spp. IMI events in each monthly interval $\left(C_{M}\right)$ as the outcome. A log link, assumption of a negative binomial distribution, and offset $\ln (I)$ (Zadoks et al., 2002) were used; $I=$ quarter-days infected in each monthly interval (study month), and $\alpha$ is the intercept in the equation $\ln \left(C_{M}\right)=$ $\alpha+\ln I$, where $C_{M}=$ cured Corynebacterium spp. IMI events in each monthly interval, and the cure rate, $\alpha$, is expressed as $\mathrm{e}^{\alpha}$. Wald $95 \%$ confidence limits were used to compare cure rates between farms.

The population level transmission dynamics were further evaluated by the basic reproduction number, $R_{0}$. The expression of $R_{0}$ is given by $R_{0}=\frac{\beta}{\mu+\alpha}$, where $\mu$ is the observed rate of entry and exit of quarters to and from the lactation compartment, and the inverse of the cure rate $(\alpha)$ is the duration of infection. A confidence interval for $R_{0}$ was calculated using $1.96 \times$ the standard error obtained from log-transformations of the monthly $R_{0}$ expressions.

\section{Model Formulation}

The transmission dynamics of Corynebacterium spp. were explored by developing a Susceptible-Infectious-Susceptible (SIS) model. The model describes a population of lactating udder quarters divided into 2 compartments: (1) $S$ denotes susceptible quarters with no Corynebacterium spp. IMI, and (2) $I$ denotes quarters affected with IMI caused by Corynebacterium spp., where the compartments represent the proportion of lactating quarters in each state. The dynamics of state transitions are illustrated in Figure 1, and the model is described mathematically by the following nonlinear ordinary differential equations (ODE):

$$
\frac{\mathrm{d} S}{\mathrm{~d} t}=-\beta S I+\alpha I+\theta_{S} N \mu-\mu S,
$$

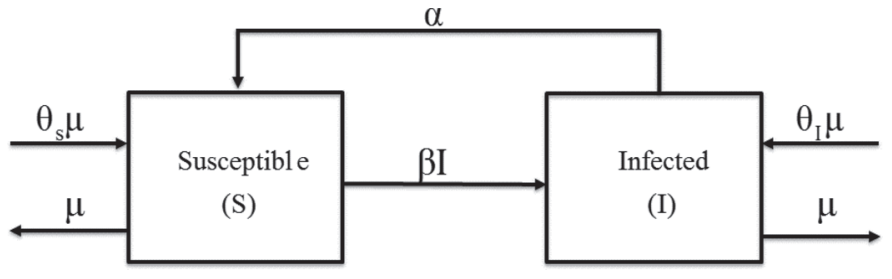

Figure 1. Schematic representation of the mathematical model of transmission of IMI with Corynebacterium spp. The boxes represent the state variables and the arrows represent the flow rates between susceptible $(\mathrm{S})$ and infected (I) states. $\beta=$ transmission parameter; $\beta I=$ daily rate of new infections; $\alpha=$ daily rate of cured quarters; $\mu$ $=$ daily rate of entry and exit of lactating quarters. The proportion of quarters into the $\mathrm{S}$ and I compartments are determined by $\theta_{\mathrm{S}}$ and $\theta_{\mathrm{I}}$, respectively.

$$
\frac{\mathrm{d} I}{\mathrm{~d} t}=\beta S I-\alpha I+\theta_{I} N \mu-\mu I
$$

where the interaction between the classes is quantified by the parameters $\alpha$ and $\beta$. The parameter $\beta$ denotes the transmission of infection from a quarter with an IMI caused by Corynebacterium spp. to a susceptible quarter (Keeling and Rohani, 2011). The parameter $\alpha$ describes the daily rate of cured quarters, and $N$ represents the sum of susceptible and infected quarters in the study at any given time. The daily rate of entry and exit of quarters to and from the lactation compartments is described by $\mu$. Entries of quarters from the fresh pen to the different compartments within the lactation pen are determined by the proportions $\theta_{S}$ and $\theta_{I}$.

The numerical resolution of the nonlinear ordinary equations of the SIS model was solved numerically by using a nonlinear programming solver of Matlab (MathWorks, Natick, MA), "ode45" solver, which is based on the Runge-Kutta method (Dormand and Prince, 1980). The numerical values of the parameters of the ODE of the SIS model, used in the numerical simulations, were obtained from the statistical analysis.

\section{RESULTS}

\section{Field Study}

In farm A, 11,744 milk samples were collected from a total of 371 cows. Among these, udder pathogens were cultured and identified in 5,021 samples. The distribution of bacterial culture results is given in Table 1. According to our definition of IMI, there were 556 Corynebacterium spp. IMI episodes during the study period, from 1,183 positive cultures; the remaining 1,618 positive samples were defined as transient colonizations. Of the 556 IMI episodes, 465 (84\%) and 200 $(36 \%)$ were associated with one or more samples having 
Table 1. Distribution of microbiological diagnoses among samples positive for one or more udder pathogens

\begin{tabular}{lcc}
\hline & \multicolumn{2}{c}{ Proportion (\%) } \\
\cline { 2 - 3 } Culture result & Farm A & Farm B \\
\hline Corynebacterium spp. & 39.5 & 23.4 \\
CNS & 39.0 & 48.2 \\
Streptococcus spp. & 15.3 & 21.5 \\
Staphylococcus aureus & 2.7 & 0.9 \\
Coliforms & 1.4 & 4.8 \\
Trueperella pyogenes & 0.4 & 0.3 \\
Streptococcus agalactiae & - & - \\
Other & 1.7 & 0.9 \\
\hline
\end{tabular}

$\geq 1,000$ or $\geq 5,000 \mathrm{cfu} / \mathrm{mL}$, respectively. The distribution of quarter samples according to this categorization is shown in Table 2. Among IMI episodes, 3 cultures of Corynebacterium spp. were isolated in association with clinical cases. These were all co-infections with other minor pathogens and were not treated. Bacteriological milk culture was performed before and after the dry period in 471 quarter samples. Of these, 37 quarters were dried off while harboring a Corynebacterium spp. IMI. At the start of the next lactation, 36 of those were cured and 1 IMI persisted. Out of 434 quarters dried off without a Corynebacterium spp. IMI, 31 quarters were infected during the dry period.

In farm B, 11,804 milk samples were collected from a total of 415 cows. Among these, udder pathogens were cultured and identified in 3,528 samples. The distribution of bacterial culture results is given in Table 1. According to our definition of IMI, there were 179 Corynebacterium spp. IMI episodes during the study period from 255 positive cultures; the remaining 816 positive samples were defined as transient colonizations. Of the 179 IMI episodes, $147(82 \%)$ and $15(8 \%)$ were associated with one or more culture results with more than 1,000 and 5,000 $\mathrm{cfu} / \mathrm{mL}$, respectively. The distribution of quarter samples according to this categorization is shown in Table 2. Among IMI episodes, no cultures were isolated in association with clinical cases of Corynebacterium spp. IMI. Bacteriological milk culture was performed both before and after the dry period in 506 quarter samples. Of these, 13 quarters were dried off while harboring a Corynebacterium spp. IMI. At the start of the next lactation, all 13 quarters were cured. Out of 493 quarters dried off without Corynebacterium spp. IMI, 3 quarters were infected during the dry period.

\section{Estimation of Transmission Parameters}

From the statistical analyses, we obtained the following values for farm $\mathrm{A}$. The transmission parameter, $\beta$, was 0.0188 (95\% CI: $0.0159-0.0222$ ), the cure rate, $\alpha$, was 0.0122 (95\% CI: $0.0098-0.0152$ ), the daily rate of udders leaving and entering the lactation pen, $\mu$, was 0.0039 (95\% CI: $0.0027-0.0050$ ), and $R_{0}$ was 1.1767 (95\% CI: $0.9269-1.5760)$.

The difference in $2 \times \log$-likelihood between the model predicting number of new IMI with $\ln \frac{S I}{N}$ used as the offset term and the model with only $\ln S$ as the offset was 138.9. With $1 \mathrm{df}$, the Chi-squared statistic predicted a highly significant effect of an existing IMI with Corynebacterium spp. on the transmission of the bacteria from infected to susceptible quarters $(P<0.001)$.

The proportion of infected by days of study, as obtained from the raw data, is presented in Figure 2. This curve shows the evolution of the infection throughout the study period. The prevalence of infection began to increase after $215 \mathrm{~d}$ of study.

From the statistical analyses, we obtained the following values for farm B. The transmission parameter, $\beta$, was 0.0239 (95\% CI: 0.0197-0.0291). The cure rate, $\alpha$, was 0.0202 (95\% CI: $0.0161-0.0253$ ), the daily rate of udders leaving and entering the lactation pen, $\mu$, was 0.0040 (95\% CI: $0.0029-0.0051$ ), and $R_{0}$ was 0.9879 (95\% CI: $0.6632-1.4846)$. The $95 \%$ CI for $\alpha$ did not overlap between farms, whereas the corresponding CI for $\beta, R_{0}$, and $\mu$ were not different between farms.

The difference in $2 \times \log$-likelihood between the model predicting number of new infections with $\ln \frac{S I}{N}$ used as the offset term and the model with only $\ln S$ as the offset was 7.27. With $1 \mathrm{df}$, the Chi-squared statistic predicted a significant effect of an existing IMI with

Table 2. Number of samples with positive Corynebacterium spp. culture results

\begin{tabular}{lccccc}
\hline & \multicolumn{2}{c}{ Corynebacterium spp. positive } & & \multicolumn{2}{c}{ Corynebacterium spp. IMI } \\
\cline { 2 - 3 } \cline { 5 - 6 } Count $(\mathrm{cfu} / \mathrm{mL})$ & Farm A & Farm B & & Farm A & Farm B \\
\hline$\geq 5,000$ & 218 & 16 & & 218 & 16 \\
$\geq 1,000$ and $<5,000$ & 330 & 140 & & 330 & 140 \\
$\geq 500$ and $<1,000$ & 409 & 298 & & 158 & 53 \\
$\geq 100$ and $<500$ & 1,844 & 617 & & 477 & 46 \\
\hline
\end{tabular}




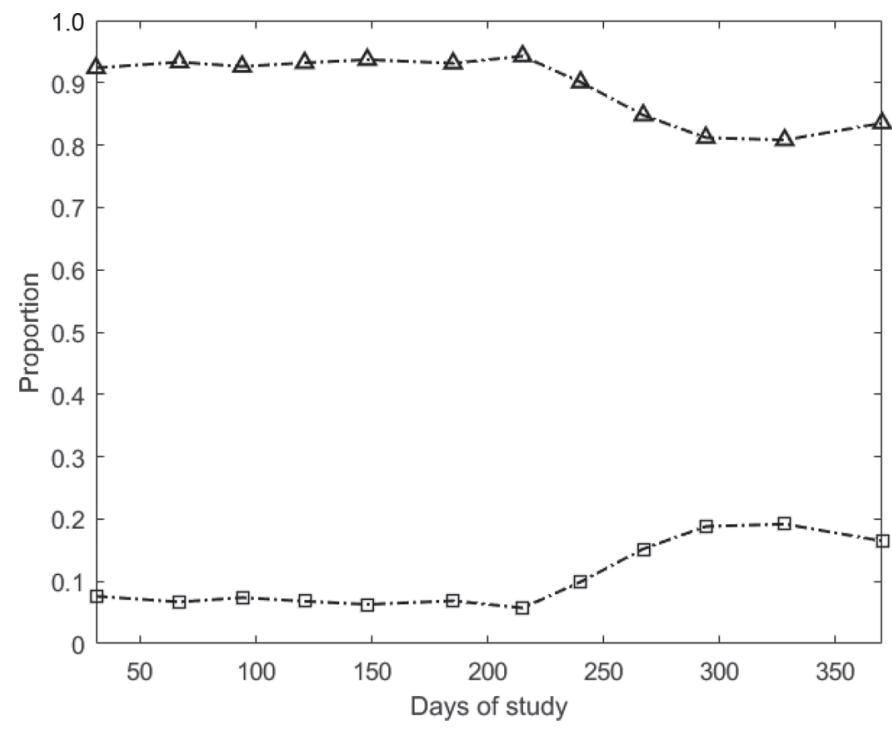

Figure 2. Proportion of quarters in farm A harboring an IMI (I; $\square$ ) with Corynebacterium spp. and susceptible quarters $(\mathrm{S} ; \Delta)$ throughout the study period.

Corynebacterium spp. on the transmission of the bacteria from infected to susceptible quarters $(P<0.01)$.

The proportion of infected quarters by time, as obtained from the raw data, is presented in Figure 3. This curve shows the evolution of the infection throughout the study period. The prevalence of infection on farm B may be characterized as uniformly low throughout the study period.

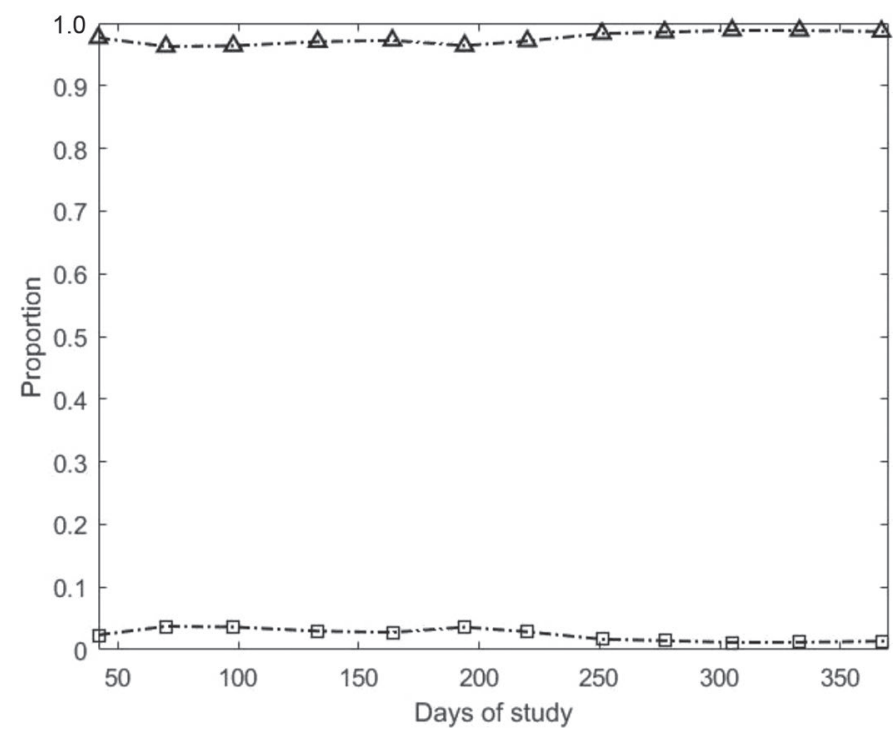

Figure 3. Proportion of quarters in farm B harboring an IMI (I; $\square$ ) with Corynebacterium spp. and susceptible quarters (S; $\Delta$ ) throughout the study period.

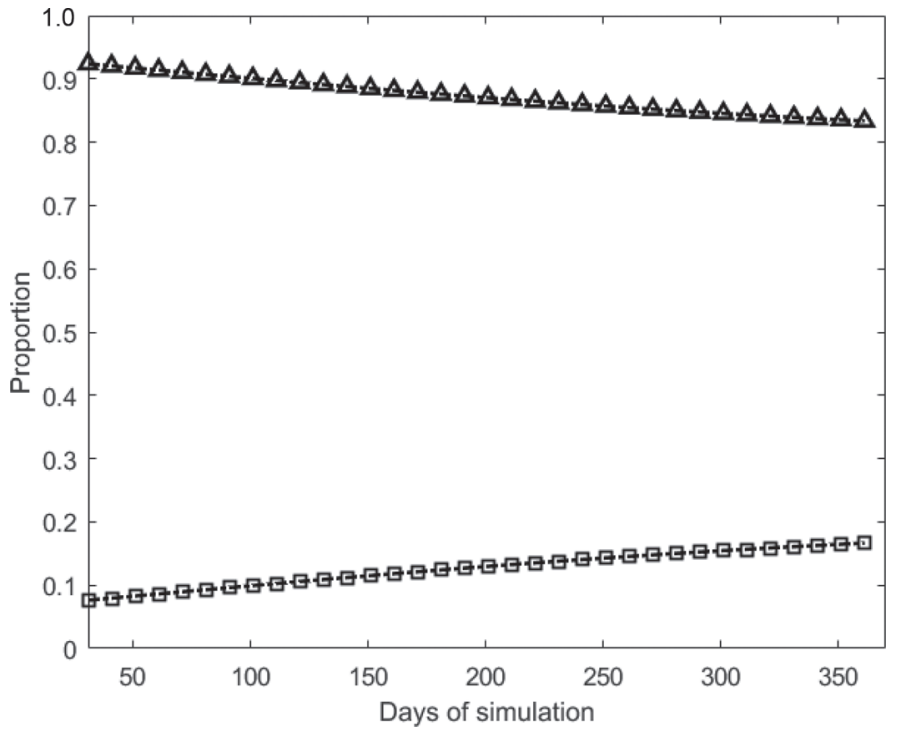

Figure 4. Simulation of the proportion of quarters in farm A harboring an IMI (I; $\square$ ) with Corynebacterium spp. and susceptible quarters (S; $\Delta$ ) using the Susceptible-Infectious-Susceptible (SIS) model. The values after initialization were $\mathrm{I}_{0}=0.07613$ and $\mathrm{S}_{0}=0.9239$.

\section{Numerical Simulations}

The proportions of $I$ and $S$ quarters from the dynamic simulation for farm A are presented in Figure 4. The proportion of $I$ quarters increased throughout the simulation period, reaching a prevalence of $16.7 \%$ at $361 \mathrm{~d}$ on farm A. Figure 5 shows the proportion of $I$ and $S$ quarters on farm B. The proportion of $I$ quarters was uniformly low throughout the simulation period on farm B.

\section{DISCUSSION}

By plotting the proportion of Corynebacterium spp. IMI by study days, we demonstrated an increase in the proportion of infected quarters from $215 \mathrm{~d}$ of study (December) and onward in farm A. We did not demonstrate a similar increase in the rate of new infections on farm B. For farm A, we obtained an $R_{0}$ of 1.18 that was not significantly different from the corresponding value for $R_{0}(0.98)$ on farm B. However, the number of IMI by Corynebacterium spp. developed differently between the 2 farms throughout the study period. Although the transmission of a pathogen is described by $R_{0}$ at the population level, it is the rate of both entry and exit of quarters, the transmission parameter, and the cure rate or duration of infection that determines the value of $R_{0}$. In our investigation, there was no significant difference between farms for the transmission parameters or the rates of entry and exit of quarters. However, 


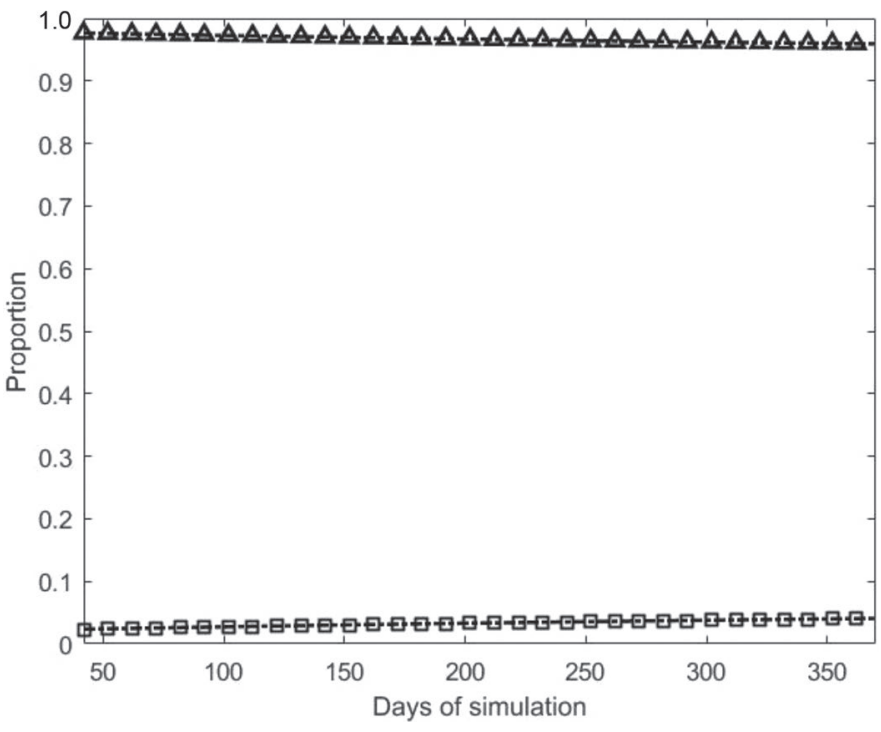

Figure 5. Simulation of the proportion of quarters in farm B harboring an IMI (I; $\square$ ) with Corynebacterium spp. and susceptible quarters $(\mathrm{S} ; \Delta)$ using the Susceptible-Infectious-Susceptible (SIS) model. The values after initialization were $\mathrm{I}_{0}=0.02346$ and $\mathrm{S}_{0}=0.9765$.

we found that cure rates were significantly different between farm A and farm B. The lower cure rate in farm A increased the $R_{0}$ for this herd, which explains the steady increase in new infections caused by preexisting IMI with Corynebacterium spp. in this farm. Correspondingly, the significance of a preexisting IMI with Corynebacterium spp. was demonstrated for both farms when we compared models with and without an existing IMI included in the offset term. The association between preexisting IMI and new infections was highly significant in farm A.

Biologically, it is plausible to relate the duration of infection to immunological characteristics of the host, or the animal's ability to eliminate an infection. It is worth noting that the cure rate during the dry period was high, with only 1 of 37 Corynebacterium spp. IMI persisting from one lactation to the next on farm A, and none out of 13 on farm B. However, we cannot quantify the degree of self-cure because blanket drycow therapy was used in the study herds.

Transmission of Corynebacterium spp. IMI depending on preexisting IMI has not, to our knowledge, been documented previously. There may be many reasons for the observed increase in new infections in our study, but it is worth noting that the increase started in December, which is the beginning of winter in New York and Vermont. Seasonal factors may thus have contributed to an increase in the infectious transmission of udder pathogens, including more wet and cold udders, damper environments, and so on. Because our diagnostics were limited to classifying at the Corynebacterium spp. level, we cannot exclude a shift toward more contagious subtypes, resulting in an alteration of transmission characteristics of the bacterial population in farm A. The deterministic state transmission simulation model shows how the epidemic evolves in a population of cows over time. This model will be suitable for modeling the long-term effect of the transmission parameters on the herd prevalence of Corynebacterium spp. IMI, and for modeling the effect of prophylactic interventions.

Very few, if any, studies have attempted to quantify the infection dynamics of Corynebacterium spp. in dairy farms. However, observational studies have indicated that the prevalence of this minor pathogen is related to the quality of postmilking teat disinfection in dairy herds (Brooks et al., 1983; Harmon et al., 1986; Hogan et al., 1994; Lam et al., 1997b; Berry and Hillerton, 2002; Williamson and Lacy-Hulbert, 2013). In accordance with this, the present study showed that udder infections contribute significantly in the transmission of Corynebacterium spp. IMI. We observed 735 cases of IMI, 3 of which were from clinical cases. From the biological perspective, transient colonization does not necessarily equal IMI. Therefore, we limited our modeling to our definition of IMI.

It should be noted that the results we obtained were from 2 herds with different prevalences of $\mathrm{Co}$ rynebacterium spp. IMI, despite being of similar size and having comparable management routines. We cultured Corynebacterium spp. from $23.9 \%$ of the quarter samples from farm A, but from only $9.1 \%$ of the quarter samples in farm B. The prevalence in farm A was relatively high compared with that reported in other publications (Brooks et al., 1983; Pitkälä et al., 2004; Green et al., 2005). In farm A, a higher proportion of the IMI episodes were associated with culture results having $>5,000 \mathrm{cfu} / \mathrm{mL}$ than in farm B. This higher shedding level might contribute to an increased transmission potential on farm A. However, the estimated transmission parameter, $\beta$, did not differ between the 2 farms. Therefore, the observed difference in duration of infection and proportion of quarters shedding $>5,000$ $\mathrm{cfu} / \mathrm{mL}$ might be attributable to host-pathogen factors associated with the ability of the cows to respond to, and clear, the infections. A study on Salmonella suggested that the prevalence of different infected states within or between herds could be due to a combined effect of host immunity, herd, and Salmonella serotype characteristics (Lanzas et al., 2008).

In the classic infectious disease epidemic SIR models (Anderson and May, 1991), the total population is divided into a susceptible compartment $(\mathrm{S})$, an infected compartment (I), and a recovered compartment (R), 
where recovered individuals are often considered to be resistant or removed from the susceptible population. In our modeling study, we adjusted the traditional SIR model with modifications specific to mastitis transmission in dairy herds, where cure and reinfection of individuals are observed, and it is assumed that recovery does not confer absolute resistance to reinfection. This could be described by an SIS model (Lam et al., 1996; White et al., 2001; Reksen et al., 2012), where the total number of quarters is divided into susceptible quarters (S) and infected quarters (I), assuming that susceptibility does not differ between naive individuals and recovered quarters.

\section{CONCLUSIONS}

The current study presents an investigation of transmission dynamics of Corynebacterium spp. IMI. The statistical analyses demonstrated that transmission of Corynebacterium spp. IMI in the 2 herds studied were influenced by preexisting Corynebacterium spp. IMI. In 1 of the 2 farms, the prevalence of Corynebacterium spp. IMI increased, consistent with an observed $R_{0}>$ 1.0 related to a low cure rate of Corynebacterium spp. IMI in this farm.

\section{ACKNOWLEDGMENTS}

The authors acknowledge the contribution of participating farm owners and farm staff. The support of our field and laboratory staff is also greatly appreciated. The data for this study were available due to a previous study on subclinical mastitis supported in part by funding from Pfizer Animal Health (Madison, NJ), USDA Cooperative State Research, Education, and Extension Service (CSREES, Washington, DC), National Research Initiative award \# 2005-35204-15651, USDA CSREES Vermont Agricultural Experiment Station Animal Health and Disease award \# VT-AH01011, and the Multi-State Mastitis Research Project USDA CSREES NE-1028 (formerly NE-1009).

\section{REFERENCES}

Anderson, R. M., and R. M. May. 1991. Infectious Diseases of Humans: Dynamics and Control. Oxford Science Publications. Oxford University Press, Oxford, UK.

Barlow, J. W., R. N. Zadoks, and Y. H. Schukken. 2013. Effect of lactation therapy on Staphylococcus aureus transmission dynamics in two commercial dairy herds. BMC Vet. Res. 9:28.

Berry, E. A., and J. E. Hillerton. 2002. The effect of selective dry cow treatment on new intramammary infections. J. Dairy Sci. $85: 112-121$.

Black, R. T., R. T. Marshall, and C. T. Bourland. 1972. Locus of mammary gland infections of Corynebacterium bovis. J. Dairy Sci. $55: 413-416$.
Blagitz, M. G., F. N. Souza, B. P. Santos, C. F. Batista, A. C. Parra L. F. Azevedo, P. A. Melville, N. R. Benites, and A. M. Della Libera. 2013. Function of milk polymorphonuclear neutrophil leukocytes in bovine mammary glands infected with Corynebacterium bovis. J. Dairy Sci. 96:3750-3757.

Brooks, B. W., and D. A. Barnum. 1984a. Experimental colonization of the bovine teat duct with Corynebacterium bovis and the effect on milk somatic cell counts. Can. J. Comp. Med. 48:141-145.

Brooks, B. W., and D. A. Barnum. 1984b. The susceptibility of bovine udder quarters colonized with Corynebacterium bovis to experimental infection with Staphylococcus aureus or Streptococcus agalactiae. Can. J. Comp. Med. 48:146-150.

Brooks, B. W., D. A. Barnum, and A. H. Meek. 1983. An observational study of Corynebacterium bovis in selected Ontario dairy herds. Can. J. Comp. Med. 47:73-78.

Diekmann, O., J. A. Heesterbeek, and J. A. Metz. 1990. On the definition and the computation of the basic reproduction ratio $\mathrm{R} 0$ in models for infectious diseases in heterogeneous populations. J. Math. Biol. 28:365-382.

Dormand, J. R., and P. J. Prince. 1980. A family of embedded RungeKutta formulae. J. Comput. Appl. Math. 6:19-26.

Green, M. J., L. E. Green, A. J. Bradley, P. R. Burton, Y. H. Schukken, and G. F. Medley. 2005. Prevalence and associations between bacterial isolates from dry mammary glands of dairy cows. Vet. Rec. 156:71-77.

Grossman, Z. 1980. Oscillatory phenomena in a model of infectious diseases. Theor. Popul. Biol. 18:204-243.

Halasa, T., K. Huijps, O. Osteras, and H. Hogeveen. 2007. Economic effects of bovine mastitis and mastitis management: A review. Vet. Q. 29:18-31.

Harmon, R. J. 1994. Physiology of mastitis and factors affecting somatic cell counts. J. Dairy Sci. 77:2103-2112.

Harmon, R. J., W. L. Crist, R. W. Hemken, and B. E. Langlois. 1986. Prevalence of minor udder pathogens after intramammary dry treatment. J. Dairy Sci. 69:843-849.

Hethcote, H. W. 2000. The mathematics of infectious diseases. SIAM Rev. Soc. Ind. Appl. Math. 42:599-653.

Hogan, J. S., E. A. Berry, J. E. Hillerton, H. Hogeveen, S. C. Nickerson, S. P. Oliver, G. M. Pighetti, P. Rapnicki, Y. H. Schukken, and K. L. Smith. 2016. Current Concepts of Bovine Mastitis. 5th ed. National Mastitis Council, Madison, WI.

Hogan, J. S., R. N. González, S. C. Harmon, S. C. Nickerson, J. W. Pankey, and K. L. Smith. 1999. Laboratory Handbook on Bovine Mastitis. 1st ed. National Mastitis Council, Madison, WI.

Hogan, J. S. K. L. Smith, D. A. Todhunter, P. S. Schoenberger, R. P. Dinsmore, M. B. Canttell, and C. S. Gabel. 1994. Efficacy of dry cow therapy and a Propionibacterium acnes product in herds with low somatic cell count. J. Dairy Sci. 77:3331-3337.

Hogeveen, H., K. Huijps, and T. J. Lam. 2011. Economic aspects of mastitis: New developments. N. Z. Vet. J. 59:16-23.

Keeling, M. J., and P. Rohani. 2011. Modeling Infectious Diseases in Humans and Animals. Princeton University Press, Princeton, NJ.

Lam, T. J., M. C. DeJong, Y. H. Schukken, and A. Brand. 1996. Mathematical modeling to estimate efficacy of postmilking teat disinfection in split-udder trials of dairy cows. J. Dairy Sci. 79:62-70.

Lam, T. J., Y. H. Schukken, J. H. van Vliet, F. J. Grommers, M. J Tielen, and A. Brand. 1997a. Effect of natural infection with minor pathogens on susceptibility to natural infection with major pathogens in the bovine mammary gland. Am. J. Vet. Res. 58:17-22.

Lam, T. J., J. H. van Vliet, Y. H. Schukken, F. J. Grommers, A. van Velden-Russcher, H. W. Barkema, and A. Brand. 1997b. The effect of discontinuation of postmilking teat disinfection in low somatic cell count herds. II. Dynamics of intramammary infections. Vet. Q. 19:47-53.

Lam, T. J. G. M. 1996. Dynamics of bovine mastitis: A field study in low somatic cell count herds. PhD Thesis. Utrecht University, Utrecht, the Netherlands.

Lanzas, C., S. Brien, R. Ivanek, Y. Lo, P. P. Chapagain, K. A. Ray, P. Ayscue, L. D. Warnick, and Y. T. Grohn. 2008. The effect of heterogeneous infectious period and contagiousness on the dynam- 
ics of Salmonella transmission in dairy cattle. Epidemiol. Infect. 136:1496-1510.

Magal, P., and S. Ruan. 2008. Structured Population Models in Biology and Epidemiology. Vol. 1936. Lecture Notes in Mathematics. Springer, Berlin, Germany.

Otto, S. P., and T. Day. 2011. Biologist's Guide to Mathematical Modeling in Ecology and Evolution. Princeton University Press, Princeton, NJ.

Pankey, J. W., S. C. Nickerson, R. L. Boddie, and J. S. Hogan. 1985. Effects of Corynebacterium bovis infection on susceptibility to major mastitis pathogens. J. Dairy Sci. 68:2684-2693.

Parker, K. I., C. Compton, F. M. Anniss, A. Weir, C. Heuer, and S. McDougall. 2007. Subclinical and clinical mastitis in heifers following the use of a teat sealant precalving. J. Dairy Sci. 90:207-218.

Pitkälä, A., M. Haveri, S. Pyorala, V. Myllys, and T. HonkanenBuzalski. 2004. Bovine mastitis in Finland 200-Prevalence, distribution of bacteria, and antimicrobial resistance. J. Dairy Sci. $87: 2433-2441$.
Rainard, P., and B. Poutrel. 1988. Effect of naturally occurring intramammary infections by minor pathogens on new infections by major pathogens in cattle. Am. J. Vet. Res. 49:327-329.

Reksen, O., Y. T. Gröhn, J. W. Barlow, and Y. H. Schukken. 2012. Transmission dynamics of intramammary infections with coagulase-negative staphylococci. J. Dairy Sci. 95:4899-4910.

White, L. J., T. J. Lam, Y. H. Schukken, L. E. Green, G. F. Medley, and M. J. Chappell. 2006. The transmission and control of mastitis in dairy cows: A theoretical approach. Prev. Vet. Med. 74:67-83.

White, L. J., Y. H. Schukken, T. J. Lam, G. F. Medley, and M. J. Chappell. 2001. A multispecies model for the transmission and control of mastitis in dairy cows. Epidemiol. Infect. 127:567-576.

Williamson, J. H., and S. J. Lacy-Hulbert. 2013. Effect of disinfecting teats post-milking or pre- and post-milking on intramammary infection and somatic cell count. N. Z. Vet. J. 61:262-268.

Zadoks, R. N., H. G. Allore, T. J. Hagenaars, H. W. Barkema, and Y. H. Schukken. 2002. A mathematical model of Staphylococcus aureus control in dairy herds. Epidemiol. Infect. 129:397-416. 